\title{
Tuberous sclerosis complex and psoriasis: A possible common pathophysiology
}

\section{Asmae Rasso1, Sara Oukarf1, Aboubakry Sow², Sara Elloudi', Hanane Baybay', Molay Hassan Farih', Fatima Zahra Mernissi ${ }^{1}$}

\author{
${ }^{1}$ Department of Dermatology, CHU Hassan II Fez, Morocco, ${ }^{2}$ Department of Urology, CHU Hassan II Fez, Morocco
}

Corresponding author: Dr. Asame Rasso, E-mail: rassoasmae@gmail.com

\begin{abstract}
Tuberous sclerosis is a rare genodermatosis characterized by multisystemic disorders: cutaneous, cerebral, ocular, bony, digestive, pulmonary, sometimes severe, especially renal and cardiac. The association of this condition with psoriasis, to our knowledge, has never been described, which may suggest a common pathophysiology. The case of a 45 -year-old male, and similar cases in the family, provides an association with skin psoriasis and tuberous sclerosis as skin and kidney manifestations. This association in a single patient suggests a possible common pathophysiology, including the common activation of mTOR. More studies are needed to prove the relationship between these two entities.
\end{abstract}

Key words: Tuberous sclerosis; Psoriasis; Bourneville-Pringle disease

\section{INTRODUCTION}

Tuberous sclerosis complex (TSC), also known as Bourneville disease or Bourneville-Pringle disease, is an autosomal dominant genetic disorder with various clinical manifestations that affects the brain, skin, kidneys, heart, and other organs [1]. The association of STB with psoriasis is very rare and suggests a common pathophysiology. We report such a rare case of tuberous sclerosis in a 45 -year-old male with psoriasis.

\section{CASE REPORT}

A 45-year-old male with no significant pathological antecedent presented himself to the urology department with low back pain. The patient had had asymptomatic cutaneous lesions since the age of six years with extension and increase in number and size, as well as similar cases in the family (father, four brothers, granddaughter, nephews, and nieces), with no notion of consanguinity in the parents, and pruriginous, erythematous, squamous lesions evolving by pushed remission since the age of ten years. The patient did not report epileptic seizures, psychomotor disorders, or other possible associated signs. A dermatological examination revealed multiple angiofibromas (Fig. la) symmetrically distributed over the centrofacial areas, fibrous cephalic plaques (Fig. 1b) sitting at the level of the forehead and scalp, a shagreen plaque with a $10-\mathrm{cm}$ long axis (Fig. lc) sitting at the left axillary level, multiple skin tags around the neck, and periungual fibromas (Figs. ld and le). Erythematous squamous plaques sitting at the knees and elbows were bilateral and symmetrical with a methodical scratching of positive pitcher; the body surface was 4\% (Fig. 2). The patient did not show any symptoms of cardiovascular, endocrine, respiratory, immune, or musculoskeletal disorders. Ultrasonography and abdominal CT revealed a multicystic kidney without pylocelical dilation with pylocelictic stones. The diagnosis of STB was retained and was associated with psoriasis. The patient benefitted from a double "J" probe uplift in the urology department and application of a topical corticosteroid on the psoriasis plaque with an improvement.

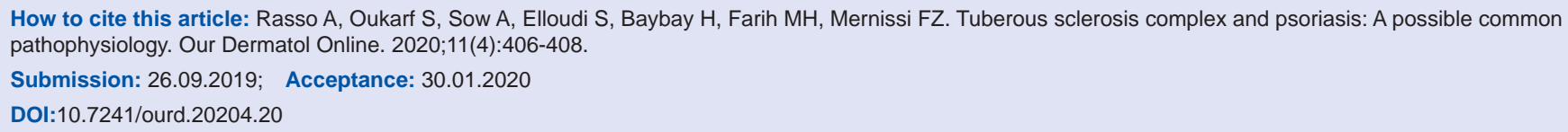




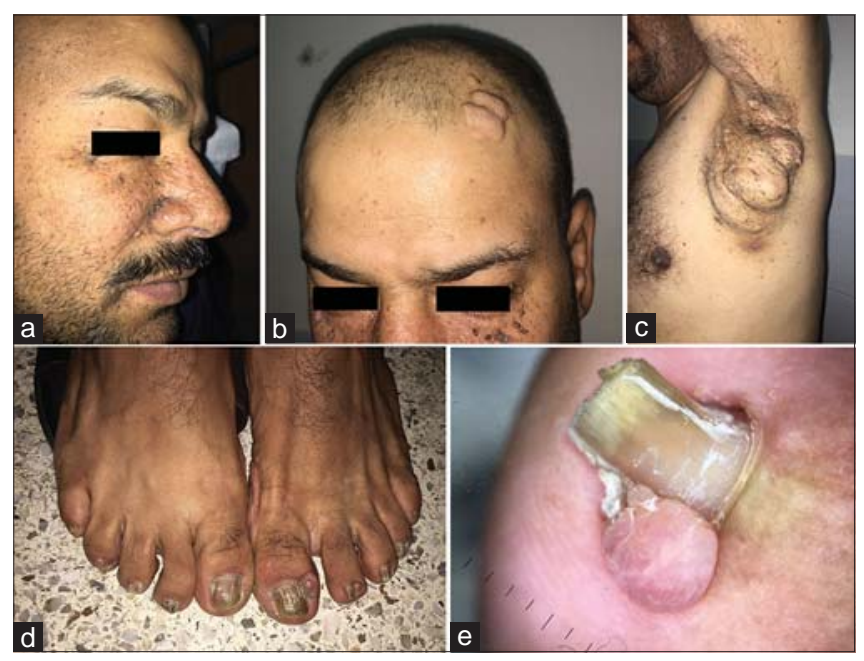

Figure 1: Clinical manifestations of tuberous sclerosis complex: (a) angiofibromas, (b) fibrous plaques, (c) a shagreen plaque, and (d) ungual fibromas and (e) their dermoscopy.

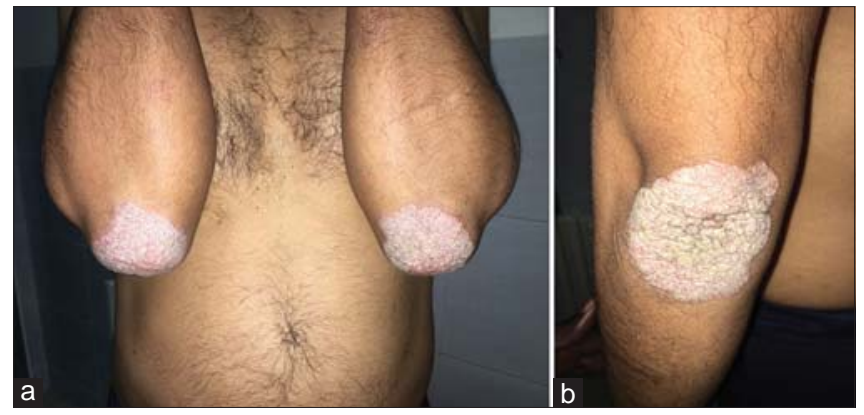

Figure 2: Bilateral and symmetrical psoriatic plaques sitting at the knees and elbows.

\section{DISCUSSION}

Tuberous sclerosis complex (TSC) is one of a group of related disorders known as neurocutaneous syndromes or phakomatoses with an incidence rate of approx. 1 in 5000-10,000 live births [2,3]. It is an autosomal dominant disease with high penetrance caused by genetic mutations in one of the TSCl or TSC2 genes [2], which results in the overactivation of mammalian target of rapamycin complex 1 (mTOR), a key intracellular regulator of cell growth and proliferation, leading to hamartomatous lesions in several organs $[3,4]$. TSC is a multisystem disorder with various clinical manifestations. The wide spectrum of clinical features results from the formation of hamartomas in various organs. Hamartomas are frequently present in the skin, brain, kidneys, heart, and, less frequently, in the lungs, retina, gingiva, bones, and gastrointestinal tract [5]. The diagnosis is based on the association of major criteria and minor criteria (Table 1) [6]. The diagnosis is made when two major criteria, or one major and two minor,
Table 1: The diagnostic criteria of tuberous sclerosis [6]

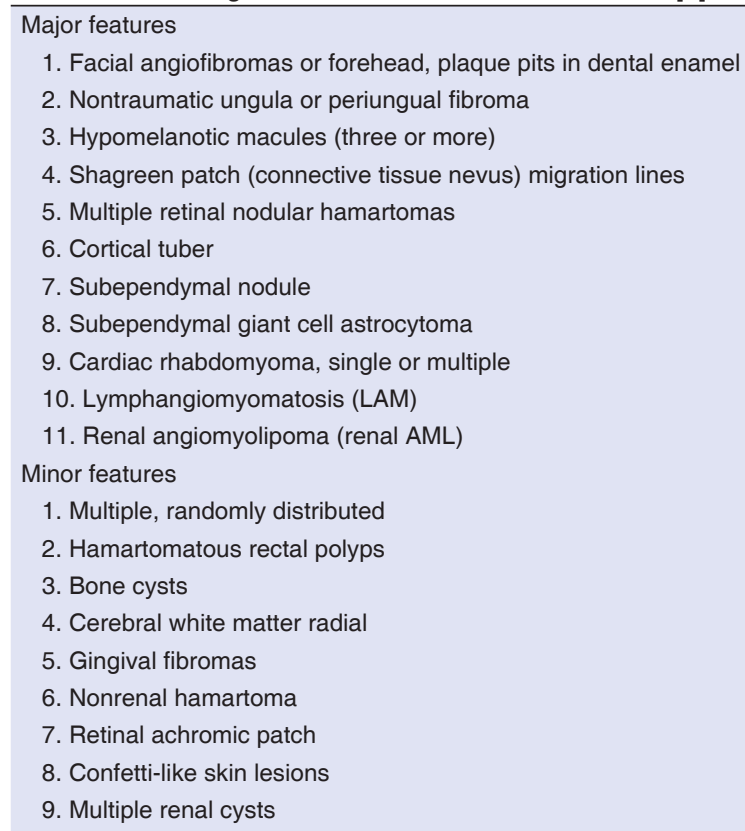

Definite TSC: either two major features or one major feature and two minor features. Probable TSC: one major and one minor feature. Possible TSC: either one major feature or two or more minor features. Note: Cortical tubers together with cerebral white matter radial migration lines are considered one feature. In patients with LAM or renal AML, other features are required for diagnosis

are fulfilled. The diagnosis and management of TSC is often challenging. The treatment involves addressing the symptoms caused by the hamartomas. Inhibitors of the mTOR pathway, such as rapamycin, have an immunosuppressive and antiproliferative action. This drug is effective in reducing the volume of the tumors.

On the other hand, psoriasis is a chronic autoimmune inflammatory skin disorder, following the proliferation and abnormal differentiation of keratinocytes, which are under the influence of several factors whose genetic component remains the most likely [7], including mutation of the genes of the chemokine, including MCP1, CCR2, and CCR5. The PSORS2 locus is a gene that is the active transcription factor in inflammation and immunity located in the region of the gene encoding the RAPTOR protein, a protein associated with mTOR regulation. Thrombin/threonine protein kinase (mTOR) regulates growth and cell proliferation in response to environmental stimuli. It is overexpressed preferentially at the psoriatic level of lesional and nonlesional skin [8]. In psoriasis, dysregulation of cytokines and growth factors may lead to the activation of the mTOR signaling system, which initiates the proliferation of keratinocytes and synovial cells responsible for psoriatic arthritis. For the first time, we explored how a dual kinase inhibitor of mTOR signal proteins may be an equally effective 
therapeutic agent for psoriasis. The association with TSC in our patient suggests the genetic predisposition of psoriasis vulgaris [9]. It blocks IL-2-induced LT proliferation via mTOR inhibition.

\section{CONCLUSION}

To our knowledge, this is the first report that describes the association of psoriasis with STB in a patient. These inflammatory diseases are chronic with mainly cutaneous manifestations and share a hereditary character and a common pathophysiology, but with different mutations.

\section{Consent}

The examination of the patient was conducted according to the principles of the Declaration of Helsinki.

\section{REFERENCES}

1. Roach ES, Gomez MR, Northrup H. Tuberous sclerosis complex consensus conference: Revised clinical diagnostic criteria. J Child
Neurol. 1998;13:624-8.

2. Caban C, Khan N, Hasbani DM, Crino PB. Genetics of tuberous sclerosis complex: implications for clinical practice. Appl Clin Genet. 2017;10:1-8.

3. Crino PB, Nathanson KL, Henske EP. The tuberous sclerosis complex. N. Engl. J. Med. 2006;355:1345-56.

4. Kwiatkowski DJ. Tuberous sclerosis: From tubers to mTOR. Ann Hum Genet. 2003;67:87-96.

5. Di Mario FJ, Sahin M, Ebrahimi-Fakhari D. Tuberous sclerosis complex. Pediatr Clin North Am. 2015;62:633-48.

6. Northrup H, Krueger DA., International Tuberous Sclerosis Complex Consensus Group. Tuberous sclerosis complex diagnostic criteria update: recommendations of the 2012 Iinternational Tuberous Sclerosis Complex Consensus Conference. Pediatr. Neurol. 2013;49:243-54.

7. Ammar M, Souissi-Bouchlaka C, Gati A. Le psoriasis: physiopathologie et immunogénétique. Pathol Biol. 2014;62:1023.

8. Buerger C. Epidermal mTORC1 Signaling Contributes to the Pathogenesis of Psoriasis and Could Serve as a Therapeutic Target. Immunol. 2008;9:2786.

9. Raychaudhuri SK, Raychaudhuri SP. mTOR signaling cascade in psoriatic disease: Double kinase mtor inhibitor a novel therapeutic target. Indian J Dermatol. 2014;59:67-70.

Copyright by Asame Rasso, et al. This is an open-access article distributed under the terms of the Creative Commons Attribution License, which permits unrestricted use, distribution, and reproduction in any medium, provided the original author and source are credited.

Source of Support: Nil, Conflict of Interest: None declared. 